Europe's Journal of Psychology, 7(2), pp. 221-240

www.ejop.org

\title{
Do positive emotions help us cope with occupational stress?
}

\author{
Michael Galanakis
}

Panteion University of Social and Political Sciences

Fotini Galanopoulou

Panteion University of Social and Political Sciences

Anastasios Stalikas

Panteion University of Social and Political Sciences

\section{Abstract}

Occupational stress is considered as one of the most important work-related psychological problems. To date, research findings demonstrate that specific coping strategies lead to positive results, via the impact of specific positive elements such as relaxation and reframing. The broaden-and-build theory of positive emotions (Fredrickson, 1998, 2001, 2003) provides an alternative approach suggesting that positive emotions experiencing leads to beneficial psychological results. In this study we examined the relationship between positive emotions and strain in a sample of 2775 professionals. The results indicate that the experiencing of positive emotions is negatively correlated with occupational strain and that overall and discrete positive emotions predict strain over and beyond stressors.

Key words: occupational stress, positive emotions, coping strategies, the broaden-andbuild theory of positive emotions.

Introduction

Occupational stress is considered to be one of the most prominent and serious psychological problems. According to the National Institute of Occupational Safety and Health (2002), 40\% of all employees experience their job as "very" or "extremely" stressful and at least $26 \%$ feel professionally exhausted. Researchers 
have studied occupational stress in relation to gender, age, profession, smoking habits, stressors in the working place, residence, tenure, recent health problems, level in the organization and trait optimism (Bakker, Demerouti, de Boer, \& Schaufeli, 2003; Cooper \& Cartwright, 1994; Galanakis, Stalikas, Kallia, Karagianni \& Karela 2009; Grzywacz \& Butler, 2005; Jansen, Peeters, de Jonge, Houkes \& Tummers, 2004; Karasek, 1979; Karasek \& Theorell, 1990; Lazarus, 2000; Major, Klein \& Ehrhart, 2002; Seigrist 1996; Van Vegchel, De Jonge, Bosma \& Schaufeli; 2005). These variables are crucial in our effort to comprehend strain levels in employees and are taken into account in our research design.

Stress is defined as an unpleasant psychological state related to emotions of fear, anxiety, disturbance, anger, sadness and grief (Botheridge 2001, 2003; Greiner, Krause, Ragland \& Fisher, 1998; Hacker, 1991; Halbesleben \& Buckley, 2004a; Motowidlo, Packard \& Manning, 1986; Schaufeli \& Kompier, 2001). Lazarus (2000) defines stress as a complex, multidimensional negative emotion. Due to the detrimental effects of stress various coping strategies have been designed and are applied at an individual or at an organizational level.

While there has been a large body of research that examines the efficacy of a variety of individual coping strategies many researchers link stress coping mechanisms to positive attributes and psychological features such as creativity, broadening, relaxation and reframing (Caulfield, Chang, Dollard, \& Elshaug, 2004; Edwards, 1988; Galanakis, Moraitou, Garivaldis, \& Stalikas, 2009; Karasek, \& Theorell, 1990; Osipow, \& Spokane, 1984, 1987).Therefore, the purpose of this study was to investigate the possibility of overall positive emotions affecting strain levels. This contributes to the extant literature by broadening our comprehension of the efficacy of positive emotions in stress coping and also reveals a new direction for the creation of innovative strategies based on positive emotions.

The broaden-and-build Theory of positive emotions

Positive emotions feel good. Plus, the balance of people's positive and negative emotions contributes to perceptions of life satisfaction (Diener \& Larsen, 1993). However these are not the only reasons that people should care about positive emotions. According to Fredrickson's Broaden-and-Build Theory (1998), positive emotions not only make us feel good in the present, but they also increase the likelihood that one will feel good in the future. That is, positive emotions trigger upward spirals toward enhanced emotional wellbeing. This proposition stems from a new perspective regarding positive emotions offered within Fredrickson's $(1998,2001$, 2003) broaden-and-build theory. 
This model posits that, unlike negative emotions, which narrow people's thoughtaction repertoires (e.g., fight or flight), positive emotions broaden people's thoughtaction repertoires, encouraging them to discover novel lines of thought or action. An incidental outcome of these broadened mind-sets is an increase in personal resources: Key to our knowledge that positive emotions trigger upward spirals is the proposition that positive emotions broaden attention and cognition. Evidence supporting this claim comes from studies that use global- local visual processing paradigms to assess biases in attentional focus (Basso, Schefft, Ris, \& Dember, 1996; Derryberry \& Tucker, 1994). Other studies have shown that positive emotions produce patterns of thought that are notably unusual, flexible, creative, and receptive (Isen, 1987). In general, positive emotions "enlarge" the cognitive context (Galanakis \& Stalikas, 2004), an effect linked to increases in brain dopamine (Ashby, Isen, \& Turken, 1999).

If positive emotions broaden attention and cognition, enabling flexible and creative thinking, they should also facilitate coping with stress and adversity (Aspinwall, 1998). Fredrickson's research findings showed that specific positive emotions (joy, interest, tranquility, amusement, awe, contentment, gratitude, hope, love, pride, and sexual desire) lead to: a) cognitive broadening and personal resources building (Fredrickson, \& Branigan, 2000), b) negative emotions' psychological stimulation decrease ("The Undoing Hypothesis", Fredrisckson, \& Levenson, 1998), c) increase of psychological resilience (Tugade, \& Fredrickson, 2004), d) activation of upward spiral mechanisms that lead progressively to psychological health and well- being (Fredrickson \& Joiner, 2002).

To date, there are only few studies that have examined the influence of positive emotions on strain levels linking variables associated to positive emotions with the occupational stress process. The few studies that have been conducted provide support to the hypothesis that positive emotions are linked to occupational strain levels. Such studies are reviewed in the section below.

Review of prior research findings

Folkman (2008) and Folkman \& Moscowitz (2000) stated that there is a lack of studies examining the role of overall positive emotions in the stress process even though there is a reasonable theoretical basis. Giga, Cooper, \& Faragher, (2003) underlined the lack of an explanatory framework as to what makes existing stress coping strategies effective. Bond \& Bunce (2000) explained the differences in emotion based vs. action based stress coping strategies through emotion regulation and 
positive to negative emotion equilibrium. Several researchers examined the importance of social support in stress coping and suggested that its function may be explained by overall positive emotions experiencing (Beehr, 1995; Beehr, Farmer, Glazer, Gutanowski, \& Nair, 2003; Caplan, Cobb, French, Harrison, \& Pinneau, 1975; Cohen, \& Wills, 1985; Kahn, \& Byosiere, 1992; Viswesvaran, Sanchez, \& Fisher, 1999). Additionally other researchers conducted studies relative to positive and negative affect and recognized the importance of positive affect in stress coping (Arvey, Bouchard, Segal, \& Abraham, 1989; Tellegen, 1982; Watson 1988; Watson, \& Clark, 1984; Watson, Clark, \& Tellegen, 1988). Israel, Baker, Goldenhar, Heaney and Schurman (1996) underlined the impact of strengthening personal resources and psychological resilience on coping actively with the environmental stressors. A similar connection has been demonstrated by Freedy and Hobfall (1994), Kline and Snow (1994) and Meichenbaum (1993) who recognized the increase of personal resources as a stress-coping factor. Finally Seligman \& Csikszenmihalyi (2000b) found that positive affect helped healthcare professionals, who worked with AIDS patients, to experience low strain levels and suggested (2000a) that positive emotions promote psychological health and well being.

Altogether, these findings indicate that stress is a widely studied variable which is linked to specific personality, behavioral and demographic variables and that coping strategies are successful in decreasing strain levels. The Broaden-and-Build Theory (Fredrickson, 1998, 2001, 2003) provides an alternative framework which suggests that overall positive emotions are linked to occupational strain, and that the success of certain coping strategies may be a result of experiencing positive emotions. Finally recent studies provide -at least- indirect support to the hypothesis that experiencing positive emotions is linked to strain reduction via associating variables related to positive emotions such as social support and positive affect.

Study rationale and research hypotheses

Fredrickson (1998, 2001, 2003) proposed that experiencing positive emotions is beneficial in multiple ways; it activates broadening and creativity, decreases negative emotions arousal, and fosters psychological resilience and well-being. Empirical results appear to support her model ((Fredrickson \& Branigan, 2000; Fredrickson \& Joiner, 2002; Fredrickson \& Levenson, 1998, Fredrickson, Tugade, Waugh, \& Larkin, 2003).

The aim of the study is to investigate the relationship of experiencing positive emotions with strain and how this relationship may differ as a function of demographic, personality or background variables. 
Specifically, the study's research hypotheses are:

1) Higher levels of positive emotions correlate to lower levels of occupational strain.

2) The relationship between overall positive emotions and occupational strain is not affected by specific control background variables (gender, age, profession, smoking habits, stressors in the working environment, residence, tenure, recent health problems, level in the organization and optimism) which have been suggested by the literature to be related to occupational strain.

3) Discrete positive emotions have differential effects on occupational strain levels.

4) Positive emotions predict greater occupational strain levels variance when combined with background, personality and demographic control variables.

\section{Method}

\section{Sample and procedure}

The sample was comprised of 2775 Greek employees, $141.80 \%$ men and $58.20 \%$ women). The average age of the participants was $M=35$ years ( $S D=11.43)$. From the total of the sample 1149 (42.10\%) participants were employed in the private sector, $640(23.50 \%)$ were employed in the public sector, 71 (2.60\%) were medical doctors, $44(1.60 \%)$ were lawyers, 56 (2.10\%) worked as military personnel, 80 (2.90\%) were selfemployed, 31 (1.10\%) were psychologists and $656(24 \%)$ worked in other professions.

Test completion was anonymous. The researchers visited participants in their working place and administered the test battery after receiving their informed consent. All participants were provided with adequate information regarding the completion of the tests. The test battery was completed in approximately 30 minutes. Individual results were sent to participants through e-mail upon completion of the study

\section{Measures}

Demographic and background control variables

This form was constructed to record specific demographic, personality and behavioral variables that influence occupational strain levels. Specifically, in this form the participants provided information regarding the following: gender, age, profession, smoking habits (non smoker, occasional smoker, frequent smoker, and very frequent smoker), residence, tenure, recent serious health problems (yes or no in the previous year), level in the organization (low, medium, high, based on their organizational chart) and trait optimism. 
Differential Emotion Scale-Modified (DES-MOD; Frederickson et al., 2003)

This scale is comprised of 21 items and assesses the experiencing of eleven positive (joy, interest, tranquility, amusement, awe, contentment, gratitude, hope, love, pride, and sexual desire) and nine negative emotions during a two weeks period time. Participants were asked to indicate the degree that they have experienced each of the emotions in the last 15 days using a 5point Likert scale $11=1$ have not experienced this emotion, $5=1$ have experienced this emotion in the maximum degree). This scale has been developed by the Fredrickson research team, has been used in many studies (e.g. Fredrickson 2003, coefficient alpha $=0.85$ ) and represents one of the very few available scales for the assessment of positive emotions. In addition to the 20 items, there is one nominal - categorical item in which participants record the one emotion that they have experienced most often in the last 15 days. This item was later used in the study for participant categorization in 11 different positive emotion groups. Along with the specific score of each of the 20 Likert items (ranging from 1 to 5), the scale provides a total score for all negative emotions (coefficient alpha $=0.73$ ) (ranging from 9 to 45), a total for all positive emotions (coefficient alpha $=0.79$ ) (ranging from 11 to 55) and a total score that indicates if the person has experienced more positive or negative emotions. This score is calculated by dividing the total of positive emotions with the total of the negative emotions. The internal consistency of the scale in our study was similar to previous studies (coefficient alpha $=0.82$ ).

Occupational Stress Inventory (OSI) (Osipow \& Spokane, 1987)

The OSI includes 92 items which are allocated in three different subscales (PSQ, ORQ and $P R Q)$. Scores are calculated on the basis of a 4 point Likert scale that ranges from Definitely Disagree (1) to Definitely Agree (4). Participants completed the following two scales from the Occupational Stress Inventory.

1) The Personal Strain Questionnaire (PSQ) includes 22 items and measures occupational strain levels (coefficient alpha=0.88) (scores range from 22-88 points). The coefficient alpha results were similar to the ones mentioned in the manual of the test from its original standardization process (coefficient alpha=0.87)

2) The Occupational Roles Questionnaire (ORQ) consists of 30 items and calculates the degree in which the working environment is stressful (coefficient alpha=0.78) (scores range from 30-120 points). The coefficient alpha results were similar to the ones mentioned in the manual of the test from its original standardization process (coefficient alpha=0.81). 


\section{Results}

For the assessment of overall positive emotions we calculated the ratio of total positive to total negative emotions per participant according the DES.MOD results and this ratio score was used in all analyses.

For the assessment of occupational strain we estimated participants' total sum of the Personal Strain Questionnaire of the OSI by adding responses to all 224 point Likert items. Participants' scores ranged between 22 points (absence of stress) to 88 points (stress overload).

For the assessment of stressors in the workplace we accumulated each participant's answers in the Occupational Roles Questionnaire and this score was used in all analyses for the second and fifth research questions. Scores ranged between 30 (relaxed workplace) to 120 points (extremely stressful workplace).

Overall positive emotions are the independent variable and occupational strain is the dependent variable throughout all the analyses.

In order to examine the first research hypothesis, regarding the relationship of positive emotions with occupational strain, a correlation analysis was conducted between the positive to negative emotions ratio score of DES.MOD and the total PSQ score.

The analysis showed that there is moderate negative correlation between overall positive emotions experiencing and occupational strain $(r=-0.53, p<0.01)$. This result suggests that the higher the overall positive emotions experienced by the individual the lower the occupational strain levels.

In order to examine the second research hypothesis as to whether the relation between overall positive emotions and occupational strain is affected by specific background variables, a partial correlation analysis was conducted. Specifically 10 variables were examined: gender, age, profession, smoking habits, stressors in the working place, residence, tenure, recent health problems, level in the organization and trait optimism.

The results showed that there is a negative $(r=-0.441)$ and statistically significant $(p<0.001)$ correlation between overall positive emotions and occupational strain. The correlation between these two variables without controlling for the impact of the 
above intervening variables was $r=-0.53, p<0.01$. In order to identify the exact impact of each one of the ten intervening variables we conducted further partial correlations analyses for each intervening variable separately. The results of these analyses showed that trait optimism has the greater intervening impact in the relation between overall positive emotions and strain (positive emotions/strain $r=-$ $0.28, p<0.05)$. This particular personality variable magnifies the identified relationship between positive emotions and occupational strain.

Moreover in relation to the second research hypothesis we examined specifically the role of profession in the relationship of overall positive emotions and occupational strain. For that reason a MANOVA analysis was conducted, which is indicated when examining the impact of two or more categorical independent variables on a single dependent variable, by comparing the statistical significance of strain level differences with the interaction of overall positive emotions (high, medium, low positive emotions and negative emotions categories) and profession (Public servants, Private sector employees, Medical Doctors, Military, Lawyers, Self employed, Psychologists) as the independent variables.

According to the MANOVA there is a statistically significant impact of the degree of experiencing positive emotions $F(3,2020)=64.607, p<0.000$ and profession $F(7$, 2020)=2.195, $p<0.05$ on occupational strain levels, but no statistically significant impact is observed for their interaction $F(18,2020)=1.143$, ns. The findings indicate that profession and overall positive emotions influence occupational strain levels independently. Nevertheless, when we examined whether the overall positive emotions - occupational strain relationship differs in various professions the analysis showed that no differential impact exists. Overall positive emotions relate to occupational strain regardless of the profession of the individual.

In relation to the third research hypothesis we examined whether specific positive emotions have differential effects on occupational strain levels by conducting an analysis of variance. Specifically, we divided participants into 11 different positive emotions groups according their answers in DES.MOD (categorical item no.21, "Which emotion have you experienced the most during the last 15 days?"). Then we compared their occupational strain levels and checked for statistically significant differences which could be attributed to specific positive emotions experiencing.

The analysis of variance showed that the mean differences in occupational strain levels were statistically significant $F(10,1613)=4.426, p<0.001$. In order to examine which positive emotions had differential effects on occupational strain levels, post hoc analyses were conducted. According to these results using the Tamhane 
criterion, statistically significant differences were observed for the emotions of joy and tranquility compared to the other nine positive emotions examined. The employees that experienced joy $(r=-0.61, p<0.001)$ and/or tranquility $(r=-0.67$, $p<0.001$ ) as the most prominent emotion during the 15 days period preceding the study had lower strain levels in comparison to those who experienced interest, amusement, awe, contentment, gratitude, hope, love, pride, and sexual desire.

Finally as far as the fourth hypothesis is concerned we examined whether positive emotions experiencing can predict occupational strain levels. For that reason a hierarchical regression analysis was conducted.

According to the results of the hierarchical regression analysis, overall positive emotions seem to influence the stressor - strain relationship. In particular, job stressors were added first in the equation and they predicted $16 \%$ of occupational strain variance. By adding "trait optimism" $27.90 \%$ of occupational strain variance was explained. With the addition of "gender" the percentage of the explained variance increased to $31.30 \%$. With the addition of "recent serious health problems" $33.10 \%$ of the variance was explained. The addition of "Smoking" increased the explained variance to $34.10 \%$. The addition of "age" increased the percentage of the predicted variance to $34.40 \%$. Finally, "overall positive emotions" increased the explained variance to $42.70 \%$. "Residence" and "profession" did not add any predictive power.

In order to avoid type I statistical error, due to the possibility of a spillover effect, we conducted regression analysis for the proposed equation following the reverse order so as to secure that overall positive emotions influence occupational strain levels rather than the opposite. The results showed that occupational strain levels explain $28.60 \%$ of the variance of "overall positive emotions" and combined with "trait optimism", "job stressors" and "tenure" they explain $36.20 \%$ of the variance of positive emotions experiencing.

Furthermore, additional regression analyses were conducted in order to estimate the impact of specific positive emotions on occupational strain levels. For this analysis the five basic positive emotions suggested by Fredrickson were examined (contentment, pride, joy, interest and love) along with the other positive emotions embedded in this research design based on the DES.MOD (tranquility, amusement, awe, gratitude, hope and sexual desire). 
According to the results love, pride, awe, amusement, tranquility, gratitude, hope, sexual desire and interest do not seem to add to the explained variance of the model, while contentment and joy add $+2.50 \%$ and $+4.40 \%$ on the explained occupational strain variance.

\section{Discussion}

The results of the present study showed a) that there is statistically significant negative correlation between experiencing positive emotions and occupational strain levels, b) that this relationship is not influenced by demographic, personality and behavioral variables or by profession, $c$ ) that specific positive emotions (joy and tranquility) exert a greater influence in reducing strain and d) that overall positive emotions predict occupational strain levels. A plausible interpretation of these findings can be given through Fredrickson's theoretical framework which suggests that positive emotions experiencing leads to cognitive broadening and personal resources building, which in turn helps employees discover new ideas and strengthens their problem solving abilities (Fredrickson, 1998). Moreover positive emotions diminish negative emotions arousal ("The antidote hypothesis", Fredrickson, 1998) and they have a direct "anti-negative" emotions effect. Finally positive emotions lead through upward spiral mechanisms (Fredrickson, 2001) to psychological resilience and well being, which help employees sustain occupational stressors and handle strain efficiently. Nevertheless the importance of these mechanisms on stress coping were not tested in the present study.

The findings reported here have a range of implications. First, they add force to recent efforts to situate positive emotions within models of stress and coping (e.g., Folkman, 1997; Folkman \& Moskowitz, 2000). Classic theoretical depictions notwithstanding, positive emotions do not disappear during times of acute and chronic stress. The work reported here joins past work (e.g., Keltner \& Bonanno, 1997; Stein et al., 1997) in demonstrating that positive emotions are indeed present and functional during distressed periods, just as they are in other circumstances. Second, together with related research (e.g., Fredrickson, Mancuso, et al., 2000; Fredrickson \& Joiner, 2002), our findings suggest that efforts to cultivate and nurture positive emotions pay off both in the stress coping procedure.

Seeking these alluring payoffs begs the question of how to cultivate positive emotions in stressful conditions. Noting that emotions cannot be instilled directly (Fredrickson, 2000), and drawing on recent work by Folkman and colleagues (Folkman, 1997; Folkman \& Moskowitz, 2000; Park \& Folkman, 1997), we suggest that 
finding positive meaning may be the most powerful leverage point for cultivating positive emotions when under pressure. Holding spiritual or religious beliefs or otherwise appreciating the meaning of life on philosophical levels can increase people's likelihood of finding positive meaning (Folkman, 1997; Frankl, 1959; Fredrickson, 2002a; Park \& Folkman, 1997). Yet with or without the infusion of the above, people can find positive meaning in daily life by reframing adverse events in a positive light, infusing ordinary events with positive value, and pursuing and attaining realistic goals (Folkman, 1997). And in contexts of stress therapy, clinicians might cultivate positive emotions by training clients in relaxation (Fredrickson, 2000, 2002b), assigning them to engage in their favorite pleasant activities (Fredrickson, 2002b; Lewinsohn \& Gotlib, 1995), and asking patients to discuss their past best of times (Joiner et al., 2001), clinical efforts that appear to accelerate the treatment process.

Our results are in line with findings of previous studies (Folkman \& Moscowitz, 2000; Giga, Cooper, \& Faragher, 2003; Lazarus 2000) and they validate them in the occupational stress territory, through a large sample of professionals and in a variety of professions, thus increasing their external validity.

The empirical validation of the above is extremely important in the level of science, society and occupation. Specifically, the discovery of the impact of positive emotions on the experience of job stress may increase the comprehension of the phenomenon and lead to the creation and the adoption of new strategies of coping with it. Additionally, the founding enforces the state of personal - centered theories that have begun to gain attention over the last years. At the same time the occurring with these positive emotions opens the way to the examination of the experience of positive dimensions in the dealing with the negative aspects which unipolars the searching interest during the previous decades.

The main limitations of the study can be grouped into five main categories. First, all data were collected through self report questionnaires and in one test session, which can lead to subjective answers and inhibits any intention to establish causal relationships. Our findings are correlational. Second, we conducted the research in the actual working place which was one way to have access to a large number of professionals but on the other hand it gave us little control over intermediate variables like employee relationships, management style, alcohol consumption or previous psychopathology. Third, given the complexity of the study and the large number of variables in the research design, we needed to exclude other important variables related to the phenomenon like personality type or locus of control. Fourth, 
even though our sample size was adequate some categories of the sample were underrepresented compared to others. For example we had a small number of lawyers and medical doctors.

Future studies may expand our findings into five possible research directions: a) Do other positive emotions, like enthusiasm, ecstasy, or the emotion of victory, play a certain role in the stress process?, b) What is the role of variables like psychological resilience, productivity, competition and group dynamics in the relationship between positive emotions and stress?, c) How can we provoke positive emotions in the workplace?, d) What is the role of personality type in the positive emotions - stress relationship? and e) Does the interaction of stressors and positive emotions predict stress levels. Answers to these questions will help us better comprehend the essence of the stress phenomenon and create new and more efficient coping strategies for promoting health and psychological well-being in the work environment.

\section{References}

Arvey, R. D., Bouchard, T. J., Segal, N. L.,\& Abraham, L. M.(1989). Job satisfaction: Environmental and genetic components. Journal of Applied Psychology, 74, 187-192.

Ashby, F.G., Isen, A.M., \& Turken, A.U. (1999). A neuropsychological theory of positive affect and its influence on cognition. Psychological Review, 106, 529-550.

Aspinwall, L.G. (1998). Rethinking the role of positive affect in self-regulation. Motivation and Emotion ,22, 1-32.

Bakker, B. A., Demerouti, E., de Boer, E., \& Schaufeli, B. W. (2003). Job demands and job resources as predictors of absence duration and frequency. Journal of Vocational Behavior, Volume 62, Issue 2, Pages 341-356.

Basso, M.R., Schefft, B.K., Ris, M.D., \& Dember, W.N. (1996). Mood and global-local visual processing. Journal of the International Neuropsychological Society, 2, 249-255.

Beehr, T. A. (1995). Psychological stress in the workplace. London: Routledge.

Beehr, T. A., Farmer, S. J., Glazer, S., Gudanowski, D. M., \& Nair, V. N. (2003). The Enigma of Social Support and Occupational Stress - Source Congruence and Gender Role Effects. Journal of Occupational Health Psychology, 8, 220-231. 
Bellarosa, C.,\& Chen, P. Y.(1997). The effectiveness and practicality of occupational stress management interventions: A survey of subject matter expert opinions. Journal of Occupational Health Psychology, 2, 247-262.

Bond, F. W. \& Bunce, D. (2000). Mediators of change in emotion-focused and problemfocused worksite management interventions. Journal of Occupational Health Psychology, 5, 156-163.

Brief, A. P. \& Weiss, H. M. (2002). Organizational behavior: Affect in the workplace. Annual Review of Psychology, 53: 279-307.

Brotheridge, C. M.(2001). A comparison of alternative models of coping: Identifying relationships among co-worker support, workload, and emotional exhaustion in the workplace. International Journal of Stress Management, 8, 1-14.

Brotheridge, C. M. (2003). The Role of Fairness in Mediating the Effects of Voice and Justification on Stress and Other Outcomes in a Climate of Organizational Change. International Journal of Stress Management, 10, 253-268.

Caplan, R. D., Cobb, S., French, J. R. P. Jr., Harrison, R. V.,\& Pinneau, S. R. Jr.(1975). Job demands and worker health: Main effects and occupational differences. Washington, DC: U.S. Government Printing Office.

Caulfield, N., Chang, D., Dollard, M. F. \& Elshaug, C. (2004). A review of occupational stress interventions in Australia. International Journal of Stress Management, 11, 149-166.

Cohen, S. \& Wills, T. A. (1985). Stress, social support, and the buffering hypothesis. Psychological Bulletin, 98, 310-357.

Cooper, C. L. \& Cartwright, S. (1994). Healthy mind, healthy organization: A proactive approach to occupational stress. Human Relations, 47, 455-470.

Davis, C.G., Nolen-Hoeksema, S., \& Larson, J. (1998). Making sense of loss and benefiting from experience: Two construals of meaning. Journal of Personality and Social Psychology, $75,561-574$.

Day, A. L. \& Livingstone, H. A. (2001). Chronic and acute stressors among military personnel: Do coping styles buffer their negative impact on health? Journal of Occupational Health Psychology, 6, 348-360. 
Decker, P., \& Borgen, F. (1993). Dimensions of work appraisal: stress, strain, coping, job satisfaction, and negative affectivity. Journal of Counseling Psychology, 40, 470-478.

Derryberry, D., \& Tucker, D.M. (1994). Motivating the focus of attention. In P.M. Neidenthal \& S. Kitayama (Eds.), The heart's eye: Emotional influences in perception and attention (pp. 167-196). San Diego: Academic Press.

Diener, E., \& Larsen, R.J. (1993). The experience of emotional well-being. In M. Lewis \& J.M. Haviland (Eds.), Handbook of emotions (pp. 405-415). New York: Guilford.

Erez, A. \& Isen, A.M. (2002). The influence of positive affect on the components of expectancy motivation. Journal of Applied Psychology. 87(6), 1055-1067.

Folkman, S. K. (2008). The case for positive emotions in the stress process. Anxiety Stress Coping. $21(1), 3-14$.

Folkman, S. K.,\& Moskowitz, J. T.(2000). Positive affect and the other side of coping. American Psychologist, 55, 647-654.

Fredrickson, B. L. (1998). What good are positive emotions? Review of General Psychology, 2, 300-319.

Fredrickson, B.L. (2000, March 7). Cultivating positive emotions to optimize health and well-being. Prevention \& Treatment, 3, Article 0001 a. Retrieved May 8, 2001, from http://journals.apa.org/prevention/volume3/pre0030001a.html

Fredrickson, B. L. (2001). The role of positive emotions in positive psychology: The broaden-and-build theory of positive emotions. American Psychologist, 56, 218-226.

Fredrickson, B. L. (2003). The value of positive emotions. American Scientist, 91, 330-335.

Fredrickson, B. L., \& Branigan, C. A. (2000). Positive emotions broaden action urges and the scope of attention. Manuscript in preparation.

Fredrickson, B. L., \& Joiner, T. (2002). Positive emotions trigger upward spirals toward emotional well-being. Psychological Science, 13, 172-175.

Fredrickson, B. L., \& Levenson, R. W. (1998). Positive emotions speed recovery from the cardiovascular sequelae of negative emotions. Cognition and Emotion, 12, 191-220. 
Fredrickson, B. L., Tugade, M. M., Waugh, C. E., \& Larkin, G. R. (2003). What good are Positive emotions in crises? A prospective study of resilience and emotions following the terrorist attacks on the United States on September 11 th, 2001. Journal of Personality and Social Psychology, 84, 365-376.

Freedy, J. R.,\& Hobfoll, S. E.(1994). Stress inoculation for reduction of burnout: A conservation of resources approach. Anxiety, Stress and Coping, 6, 311-325.

Galanakis M., Moraitou M., Garivaldis F., \& Stalikas A. Factorial Structure and Psychometric Properties of the Maslach Burnout Inventory (MBI) in Greek Midwives. Europe's Journal of Psychology 4/2009, 52-70.

Galanakis M., \& Stalikas A. (2007). The role of positive emotions experiencing in team effectiveness. Psychology, The Journal of the Hellenic Psychological Society, 14(1), pp. 42-56, Ellinika Grammata, Elpse: Greece.

Galanakis M., Stalikas A., Kallia H., Karagianni C., \& Karela C. (2009). Gender differences in experiencing occupational stress: the role of age, education and marital status. Stress and Health, 25, 397-404.

Giga, S. I., Cooper, C. L., \& Faragher, B.(2003). The development of a framework for a comprehensive approach to stress management interventions at work. International Journal of Stress Management, 10, 280-296.

Grandey, A. A. (2003). When the show must go on: surface acting and deep acting as determinants of emotional exhaustion and peer rated service delivery. Academy of management Journal, 46(1), 86-96.

Greiner, B.A., Krause, N., Ragland, D.R., \& Fisher, J.M. (1998). Objective stress factors, accidents, and absenteeism in transit operators: a theoretical framework and empirical evidence. Journal of Occupational Health Psychology. 3(2), 130-46.

Grzywacz, J. G., \& Butler, A. B. (2005). The Impact of Job Characteristics on Work-toFamily Facilitation: Testing a Theory and Distinguishing a Construct. Journal of Occupational Health Psychology. 10(2), 97-109.

Hacker, W. (1991). Objective work environment: analysis and evaluation of objective work characteristics. Paper presented to: A Healthier Work Environment: Basic Concepts \& Methods of Measurement. Hogberga, Lidingo, Stockholm. 
Halbesleben, J. R. B., \& Buckley, M. R. (2004a). Burnout in Organizational Life. Journal of Management, 30(6), 859-879.

Israel, A. B., Baker, A. B., Goldenhar, M. L., Heaney, A. C., \& Schurman, J. S. (1996). Occupational Stress, Safety, and Health Conceptual Framework and Principles for Effective Prevention Interventions. Journal of Occupational Health Psychology, 3, 261286

Ivancevich, J. M., Matteson, M. T., Freedman, S. M. \& Phillips, J. S. (1990). Worksite stress management interventions. American Psychologist, 45, 252-261.

Janssen, M. P., Peeters C. W. M., de Jonge, J., Houkes, I., Tummers, E. R. G. (2004). Specific relationships between job demands, job resources and psychological outcomes and the mediating role of negative work-home interference. Journal of Vocational Behavior, 65(3), 411-429.

Kahn, R. L.,\& Byosiere, P.(1992). Stress in organizations. (In M. D. Dunnette \& L. M. Hough (Eds.), Handbook of industrial and organizational psychology (2nd ed., pp. 571-650). Palo Alto, CA: Consulting Psychologists Press.

Karasek, R. A. (1979). Job demands, job decision latitude and mental strain: Implications for job redesign. Administrative Science Quarterly, 24, 285-308.

Karasek, R. A. \& Theorell, T. (1990). Healthy work: Stress, productivity, and the reconstruction of working life. New York: Basic Books.

Kenny, D., \& Cooper, C. (2003). Introduction - Occupational Stress and Its Management. International Journal of Stress Management, 10, 275 - 279.

Kline, M. L. \& Snow, D. L. (1994). Effects of a worksite coping skills intervention on the stress, social support, and health outcomes of working mothers. The Journal of Primary Prevention, 15, 105-121.

Kompier, M. A., Cooper, C. L.,\& Geurts, S. A.(2000). A multiple case study approach to work stress prevention in Europe. European Journal of Work and Organizational Psychology, 9, 371-400.

Law, K. S., Wong, C., \& Song, L. J. (2004). The Construct and Criterion Validity of Emotional Intelligence and Its Potential Utility for Management Studies. Journal of Applied Psychology. 89(3), 483-496. 
Lazarus, R. S. \& Folkman, S. (1984). Stress, coping, and appraisal. New York: Springer.

Lazarus, R. S. (1991). Psychological stress in the workplace. In P. L. Perrewé (Ed.), Handbook on job stress (pp. 1-13). Corte Madera, CA: Select Press.

Lazarus, R. S. (1993a). Coping theory and research: Past, present, and future. Psychosomatic Medicine, 55, 234-247.

Lazarus, R. S. (1993b). From psychological stress to the emotions: A history of changing outlooks. Annual Review of Psychology, 44, 1-21.

Lazarus, R. S. (2000). Toward better research on stress and coping. American Psychologist, 55, 665-673.

Lazarus, R. S., Averill, J. R., \& Opton, E. M. Jr. (1970). Toward a cognitive theory of emotions. In M. Arnold (Ed), Feelings and Emotions. New York: Academic Press.

Major V. S., Klein K. J., \& Ehrhart M. G. (2002). Work time, work interference with family, and psychological distress. Journal of Applied Psychology, 87(3), 427-36.

Meichenbaum, D. (1993). Stress inoculation training: A 20 year update. In P. Lehrer \& K. Woolfolk (Eds.), Principles and practice of stress management (2nd ed., pp. 373-406). New York: Guilford Press.

Morris, J. A., \& Feldman, D. C. (1996). The dimensions, antecedents and consequences of emotional labour. Academy of management review, 21 (4), 986-1010.

Motowidlo, S. J., Packard, J. S., \& Manning, M. R.(1986). Occupational stress: Its causes and consequences for job performance. Journal of Applied Psychology, 71, 618-629.

Murphy, L. R. (1996). Stress management in work settings: A critical review. American Journal of Health Promotions, 11, 112-135.

Newman, J. E. \& Beehr, T. A. (1979). Personal and organizational strategies for handling job stress: A review of research and opinion. Personnel Psychology, 32, 1-43.

$\mathrm{NIOSH}$ (2002). The changing organization of work and the safety and health of working people - Knowledge gaps and research directions (No. DHHS (NIOSH) 2002-116): Department of Health and Human Services, Centers for Disease Control. 
Osipow, S. H. \& Spokane, A. (1984). Measuring occupational stress, strain, and coping. Applied Social Psychology Annual, 5, 67-86.

Osipow, S. H. \& Spokane, A. R. (1987). Manual for the Occupational Stress Inventory. Odessa, FL: Psychological Assessment Resources.

Richman, L. S., Kubzansky L., Maselko J., Kawachi I., Choo P., \& Baver M. (2005). Positive emotion and health: Going beyond the negative. Health psychology, 24(4), pp. 422429.

Schaubroeck, J., \& Jones, J. R. (2000). Antecedents of Workplace Emotional Labor Dimensions and Moderators of Their Effects on Physical Symptoms. Journal of Organizational Behavior, 21 (2), Special Issue: Emotions in Organization, 163-183.

Schaufeli, W. B. \& Kompier, M. A. J.(2001). Managing job stress in the Netherlands. International Journal of Stress Management, 8, 15-34.

Seligman, M. E. P.,\& Csikszentmihalyi, M. (2000a). Positive psychology. Special Issue. American Psychologist, 55.

Seligman, M. E. P., \& Csikszentmihalyi, M. (2000b). Positive psychology: An introduction. American Psychologist, 55, 5-14.

Semmer, N. K.(2003). Job stress interventions and organization of work. In J. C. Quick \& L. E. Tetrick (Eds.), Handbook of occupational health psychology (pp. 325-354). Washington, DC: American Psychological Association.

Shiota, M. N., \& Keltner, D. (2002). The Differential Positive Emotion Scale: Trait experience of eleven affects. Unpublished manuscript, University of California, Berkeley.

Siegrist, J. (1996). Adverse health effects of high-effort/low-reward conditions. Journal of Occupational Health Psychology, 1, 27-41.

Stein, N.L., Folkman, S., Trabasso, T., \& Richards, T.A. (1997). Appraisal and goal processes as predictors of psychological well-being in bereaved caregivers. Journal of Personality and Social Psychology, 72, 872-884.

Tellegen, A. (1982) Brief Manual for the Multidimensional Personality Questionnaire. Unpublished manuscript, University of Minnesota, Minneapolis. 
Tugade, M. M. \& Fredrickson, B. L. (2004). Resilient individuals use positive emotions to bounce back from negative emotional experiences. Journal of Personality and Social Psychology, 86, 320-333.

Van der Hek, H.,\& Plomp, H. N.(1997). Occupational stress management programmes: A practical overview of published effect studies. Journal of Occupational Medicine, 47, 133-141.

Van der Klink, J. J. L., Blonk, R. W. B., Schene, A. H., \& Van Dijk, F. J. H.(2001). The benefits of interventions for work-related stress. American Journal of Public Health, 91, 270-276.

Van Vegchel, N., De Jonge, J., Bosma, H., \& Schaufeli, W. (2005). Reviewing the effortreward imbalance model: drawing up the balance of 45 empirical studies. Social Science \& Medicine, 60(5), Pages $1117-1131$.

Viswesvaran, C., Sanchez, J. I., \& Fisher, J. (1999). The role of social support in the process of work stress: A meta-analysis. Journal of Vocational Behavior, 54, 314-334.

Watson, D. (1988). Intraindividual and interindividual analysis of positive and negative affect: Their relation to health complaints, perceived stress, and daily activities. Journal of Personality and Social Psychology, 54, 1020-1030.

Watson, D. \& Clark, L. A. (1984). Negative affectivity: The disposition to experience negative emotional states. Psychological Bulletin, 96, 465-490.

Watson, D., Clark, L. A. \& Tellegen, A. (1988). Development and validation of brief measures of positive and negative affect: The PANAS scales. Journal of Personality and Social Psychology, 54, 1063-1070.

Weiss, H. M. \& Cropanzano, R. (1996). Affective events theory: A theoretical discussion of the structure, causes and consequences of affective experiences at work. Research in Organizational Behavior, 18, 1-74.

About the authors:

Dr. Galanakis Michael completed his studies in Psychology, at the National Kapodistrian University of Athens, at the department of Philosophy, Pedagogic and Psychology in 1999. He holds a Masters Degree (MSC) in Economical and Organizational Psychology from Panteion University of Social and Political Sciences (2003). In 2009 he received his PhD in Organizational Psychology from Panteion University of Social and Political 
Sciences. His research interests include topics such as occupational stress, team effectiveness, motivation, job satisfaction and professional behavior. He has participated in several psychological conferences in Greece and abroad. He has also published several prototype research projects in scientific journals such as "Stress and Health", and "Psychology". He is a member of the International Association of Applied Psychology since 2008 and of the Greek Personnel Management Association since 2008.

Address for correspondence: Galanakis Michael, Panteion University of Social and Political Sciences, 10A Panagi Tsaldari Street, Kifisia, Athens, Greece, 14561 Mail: galanakismichael@hotmail.com

Galanopoulou Fotini holds a B.SC. Degree in Psychology from Panteion University of Social and Political Sciences. Her research interest includes variables such as occupational stress, well being and psychological Health. She is currently working as a Psychologist and seeking her entrance in a Masters University programme.

Dr. Stalikas Anastasios received his Bachelor Degree in Psychology from Concordia University in Montreal, Canada. He holds a Masters Degree in Clinical and Consulting Psychology from the University of Ottawa. He received his PhD in Clinical and Consulting Psychology from the University of Ottawa in 1991. He has been employed as a Psychology Professor in McGill University, University of Athens and Cretan University. From 1998 until today he works as a Psychology Professor in Panteion University of Social and Political Sciences. His research interests include variables from clinical, consulting and organizational psychology, while he specializes in methodology and statistics. He has published several articles in major international and national journals. He is the author of a large number of scientific psychology books. He is an active member of psychological associations such the American Psychological Association, the Canadian Psychological Association, the Ordres des Psychologues du Québec, the Society for psychotherapy Research and the Greek National Psychology Association. 